
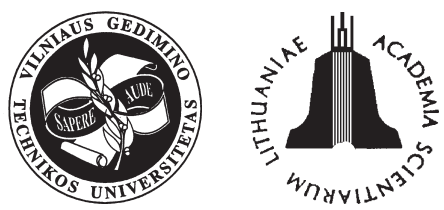

ISSN 1648-4142 TRANSPORT

http:/www.vtu.lt/english/editions

TRANSPORT - 2005, Vol XX, No 3, 123-128

\title{
THE INFLUENCE OF COOLANT SCALE DEPOSIT INSIDE THE INTERNAL COMBUSTION ENGINE ON THE PISTON AND CYLINDER DEFORMATIONS
}

\author{
Giedrius Garbinčius ${ }^{1}$, Vilius Bartulis ${ }^{2}$, Robertas Pečeliūnas ${ }^{3}$, Saugirdas Pukalskas ${ }^{4}$ \\ ${ }^{1,3,4}$ Dept of Automobile Transport, ${ }^{2}$ Dept of Transport Technolog. Equip., Vilnius Gediminas Technical University, \\ J. Basanavičiaus g. 28, LT-03224 Vilnius, Lithuania \\ E-mail:1,3,4tiauto@ti.vtu.lt, ${ }^{2}$ vilius.bartulis@ti.vtu.lt
}

Received 2005-01-16; accepted 2005-03-25

\begin{abstract}
This paper presents the analysis of the influence of engine coolant scale deposits on the deformations in the piston - cylinder pair. The results of carried out calculations enable to make more precise evaluation of cylinder repair dimensions. The aim of calculations was to establish how the thermal gap between the piston and cylinder varies in accordance with variations of heat transfer conditions, i.e. when on the outer surface of the cylinder a layer of scale deposits is formed.
\end{abstract}

Keywords: internal combustion engine; coolant; piston; cylinder; deformations.

\section{Introduction}

The cooling system of any internal combustion engine (ICE) serves for cooling of the engine parts and for heat transfer to the outer environment. This heat is a part of the heat formed in the combustion process which was not converted into the indicated power and not removed out with the exhaust gas. The volume of such heat can be found by drawing up the heat balance and it is often about 30 percent of total heat formed in the cylinders. Mostly in modern ICEs the cooling systems are of a liquid type which in many cases have the advantage over the air type ones. Conventional ICE cooling systems of road vehicles are of one loop type, i.e. the coolant at first flows and cools the outer surfaces of cylinders and after that flows into the cooling passages in the cylinder head [1]. The good quality service and exploitation of the cooling system guarantee the optimal temperatures of the piston - cylinder and cylinder head components. The influence of these temperatures is of great importance on ICE power and economy indications and also on the total resource of ICE. With the purpose of the increase of the efficiency and reliability of ICEs some years ago the research and design of so-called "precise cooling" systems have begun [2]. In the case of insufficient heat transfer of the engine the lubrication conditions in frictional pairs become poor, a component overheat arises, it can cause a dangerous decrease of gaps in frictional pairs. Under such condi- tions the intensity of wear by friction of ICE components significantly increases, the danger of component sticking or even breakage arises. Such working conditions are particularly dangerous for components of the piston-cylinder pair.

\section{The main requirements to be satisfied by the cool- ants}

The coolant is an especially important component of every cooling system. It namely does the job of heat transfer from hot surfaces to the surrounding environment. The selection of some coolant for ICE cooling system is influenced by many, often even contradictory, factors. The best coolant can be simply water for its high heat capacity and conductivity and low viscosity. Its coefficient of heat transfer is good. But other water parameters are improper for ICE cooling systems. Its high freezing temperature, low boiling temperature and some other parameters completely do not satisfy the requirements facing the coolants. Therefore pure water today is seldom used in ICE cooling systems. For its specific working conditions the coolant needs to distinguish itself in specific physical, chemical and exploitational properties. The main requirements to be satisfied by the coolants are below [3]. The coolants must:

- $\quad$ not freeze at negative temperature and not boil at ICE working temperatures;

- $\quad$ have good thermal properties; 
- be chemically stable under different working conditions;

- not form scale deposits and sediments on the inner surfaces of the system;

- not provoke corrosion of ferrous as well as nonferrous metals, not destroy rubber and plastic components;

- $\quad$ not foam;

- be of low toxicity;

- be fireproof.

These requirements best of all are met by a coolant consisting of water, ethylenglycol $\left(\mathrm{C}_{2} \mathrm{H}_{4}(\mathrm{OH})_{2}\right)$ and special additives. Such mixtures now are of the widest use. They are made based on the requirements recommended by automotive manufacturers and usually consist of $50 \%$ of distilled or softened by other means water and $50 \%$ of ethylenglycol with special additives. The boiling temperature of such coolant is $107^{\circ} \mathrm{C}$ and its freezing temperature is $-36^{\circ} \mathrm{C}$.

For the protection of users the greatest states have established some minimum quality requirements for coolants which are also recognized by the main automotive manufacturers. Regardless of this the most of such manufacturers apply their own specific requirements to the coolants for use in their vehicles. The automotive manufacturers and standardizing organizations after pertinent research and tests for correspondence to quality requirements grant the certificates of approval to a Standard. Here are some of such world-wide Standards: ASTM D3306, ASTM D 4985, SAE J 1034, SAE J 814, SAE J 1941 (USA); BS 6580, BS 5117 (GB); AFNOR NF R15-601 (France); FVV HEFT R 443 (Germany) and others [3]. These Standards describe in detail the requirements which are to be satisfied by physical and chemical properties of coolants and methods and procedures of their verification.

\section{Formation of scale deposit in the cooling system of an internal combustion engine}

As time goes, properties of coolants are changing themselves but, unfortunately, not to a good direction. On the hottest components of ICE (on cylinders, cylinder heads) there begins the formation of scale deposits which is influenced by a lot of factors. The main among them are the following [1]:

hardness of water; the harder water in the coolant results in the greater amount of the deposits; at temperatures exceeding $85^{\circ} \mathrm{C}$ (there takes place the fall out of bicarbonatic calcium $\mathrm{Ca}\left(\mathrm{HCO}_{3}\right)_{2}$ and magnesium $\mathrm{Mg}\left(\mathrm{HCO}_{3}\right)_{2}$ salts which further disintegrate into indissoluble salts $\mathrm{CaCO}_{3}$ and $\mathrm{MgCO}_{3}$;
- temperature; the higher temperature results in faster formation of indissoluble calcium and magnesium carbonates which stick to the inner walls of the cooling system;

- character of flow of the coolant; the scale deposits formation takes place mainly on the hot side of the cooling system and the spots where the flow stream is turbulent or its speed is low;

- $\quad$ air bubbles; any formation of air bubbles (boiling at hot zones) increases the intensity of the formation of scale deposits in that area;

- $\quad \mathrm{pH}$ indication; its increase increases the possibility of the formation of scale deposits.

For the estimation of the incidence of formation of scale deposits on the walls of ICE-s cooling system the research was carried out. 18 cylinder blocks, being in need of overhaul were gathered together from various automobile repair shops. Side walls of all ICE blocks were cut off with the purpose of inspection it there were any scale deposits on the cylinder walls or not. In 14 of all 18 ICE-s (or $78 \%$ ) the scale deposits were observed. They were of different thickness and unevenly distributed along the perimeter of the cylinder as well as along the height of the cylinder (Fig 1).
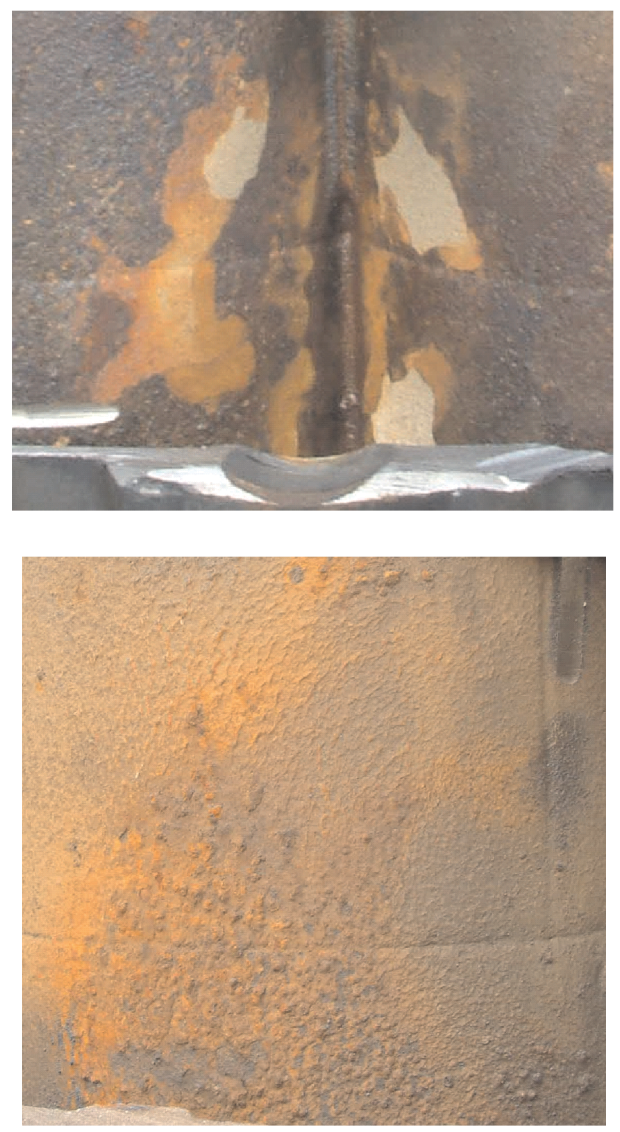

Fig 1. Scale deposit on the cylinder surface 


\section{Heat transfer inside the engine combustion cham- ber}

It is known that heat transfer effects internal combustion engine performance, efficiency and emissions. As far as performance is concerned, cooling for the cylinder head, cylinder and piston is desired because of the problems such as thermal stresses in regions of high heat flux, deterioration of the lubricating oil film, and knock and preignition in spark ignition engines. On the other hand, an increase of heat transfer to the combustion chamber walls will lower the gas temperature and pressure within the cylinder and this reduces the work per cycle transferred to the piston. Heat transfer from the working gas to the cooling system of a conventional spark ignition engine accounts for up to $30 \%$ of the fuel energy. About $50 \%$ of this energy is lost through the piston and $30 \%$ through the head [3]. Thus efficiency is affected by the magnitude of engine heat transfer. Changes in gas temperature due to the heat transfer also impact pollutant emission formation processes. Generally, a higher temperature in the cylinder during combustion can cause an increment in $\mathrm{NO}_{\mathrm{x}}$ emissions and fuel consumption $[4,5]$.

The heat transfer from the combustion gases to the combustion chamber walls is driven by the relatively large temperature difference between the combustion gases and the engine walls and can be described by forced convection relationships inside the combustion chamber. Although the flow inside the combustion chamber is clearly turbulent and compressible, as well as time and space-varying analytical solutions developed thus far are limited to laminar and simplified geometry turbulent flow.

During engine running elevated temperatures will decrease the allowable stress or strength of material and then cause serious problems such as seizures and cracks on the piston head, while the coupled thermal and mechanical deformations will influence the clearance and then cause principally scuffing and friction which shorten piston life and degrade engine performance. In order to develop a comprehensive and global model that describes the dynamic behavior coupled with the lubrication of the piston, the thermomechanical behavior of the piston must first be known.

The first studies relating to thermal piston analysis began in the 1940s with the development of the electrical analogy method [6] and simple analytical method [7, 8], which are used for calculating the . field temperature in the piston in order to obtain cooling of the piston. At the beginning of the 1960s rheological models were developed, making it possible to take into account the geometric complexity of the piston [9].
With the development of the finite element method numerical models appeared, starting from the beginning of the 1980s. Li [10] used a three-dimensional finite element model of an aluminum diesel engine piston to calculate operating temperatures and thermal and mechanical deformations due to thermomechanical loads. He shows that skirt contours play an important part in the reduction of scuffing and friction. Finite elements models of pistons for high-speed direct injection diesel engines were developed and showed the influence of the thermal interaction on the design and the development of the pistons [1115].

\section{The finite element model of the piston and cylin- der}

In this article the analysis using three-dimensional finite elements of the thermomechanical behaviour of a spark ignition engine piston and cylinder is presented [16]. Applications are made on the solid skirt piston made of aluminum alloy of the standard TOYOTA 18R-G engine and cylinder is made of gray cast iron. The piston is subjected to the action of the thermal loads due to the heat transfer from the head to the body. The response of the model which is simulated by critical loads makes it possible to know and to analyze the operating temperatures, the corresponding thermal expansion and the thermomechanical deformations and stresses. The analysis was performed with the help of the CosmosDesign STAR software.

A computer aided design (CAD) technique is used to draw the piston and cylinder geometry in order to represent the real structure of the piston and cylinder as accurately as possible. An automatic mesh generation which uses a tetrahedral finite element leads us to adopt a fine mesh of 56450 elements to the piston and 32423 elements to the cylinder.

The heat transfer analysis is limited to the steady state case. The piston and the cylinder are subjected to uniform flux through an average thermal engine cycle. It is assumed that the piston is subjected to free convection exchanges with its surroundings. Engine power that describes engine thermal load is $80 \%$ of the nominal one. To analyse the thermal transfer process the piston and the cylinder are treated as an isolated system which is in equilibrium with its surrounding. Models of thermal transfers between combustion gases and the walls of the combustion chamber on the one hand, and the walls of the piston and the oil of cooling on the other hand, are obtained by experimental measurements $[13,17]$ based on the principle of surface thermocouples of Bendersky as well as by empirical correlations $[18,19]$. The empirical corre- 
lations use the properties of the coolant, the speed of the engine, the pressure and the temperature of combustion gases. The conditions of heat transfer for the piston and the cylinder were given by boundary conditions of third kind, i. e. by the heat transfer coefficients and by temperatures of environment of surfaces through which the heat transfer goes in and out. The values of these parameters determining the heat transfer are (direction, heat transfer coefficient, temperature):

- from combustion gas to the head of the piston, $350 \mathrm{~W} / \mathrm{m}^{2} \mathrm{~K}, 750^{\circ} \mathrm{C}$ (gas);

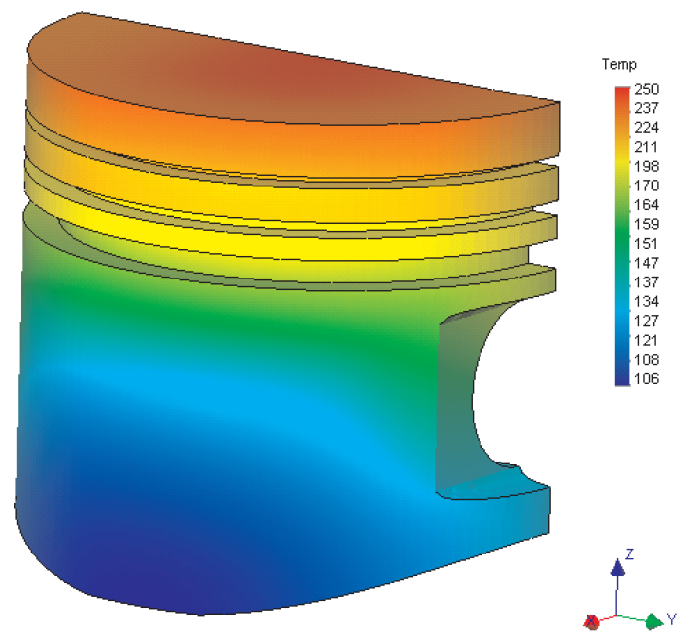

Fig 2. Temperature distribution in the piston

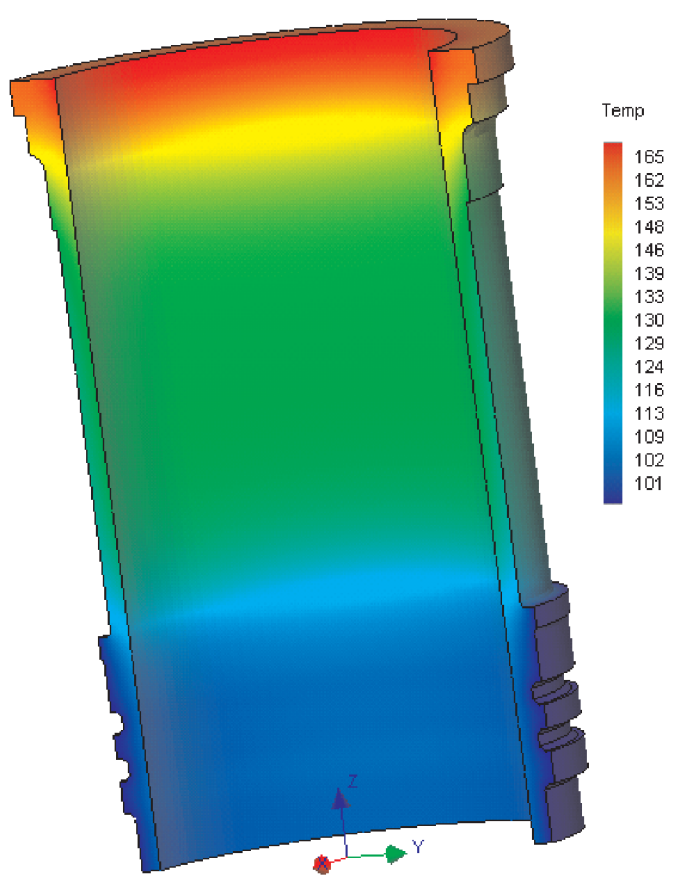

Fig 3. Temperature distribution in the cylinder
- from the inner surface of the piston to the oil mist, $250 \mathrm{~W} / \mathrm{m}^{2} \mathrm{~K}, 90^{\circ} \mathrm{C}$ (outer mist);

- from the upper side of the piston ring groove to the ring, $1500 \mathrm{~W} / \mathrm{m}^{2} \mathrm{~K}, 250^{\circ} \mathrm{C}$;

- from the lower side of the piston ring groove to the ring, $800 \mathrm{~W} / \mathrm{m}^{2} \mathrm{~K}, 250{ }^{\circ} \mathrm{C}$;

- from the piston skirt, $1000 \mathrm{~W} / \mathrm{m}^{2} \mathrm{~K}, 110{ }^{\circ} \mathrm{C}$;

- from combustion gas to the cylinder, $300 \mathrm{~W} / \mathrm{m}^{2} \mathrm{~K}$, $750{ }^{\circ} \mathrm{C}$ (gas);

- from the cylinder to the coolant, $2300 \mathrm{~W} / \mathrm{m}^{2} \mathrm{~K}$, $95^{\circ} \mathrm{C}$ (coolant).

The calculations were performed for the case, when the thickness of the scale deposits on the cylinder outer surface was from 0 to $1 \mathrm{~mm}$ and the heat transfer coefficient of the deposits layer was $1,5 \mathrm{~W} / \mathrm{m}^{2} \mathrm{~K}$.

The calculations resulted in temperatures, stress, deformations in the piston and cylinder and displacements in finite elements nodes. These results and values of initial conditions were used for the calculations of the thermal deformations of the piston and the cylinder for corresponding thermal conditions of ICE.

The thermal transfer model described above is adopted in this study. The heat flux from combustion gases in the combustion chamber is transferred by free convection on the head of the piston and then crosses the piston where a flow part is exchanged by conduction inside the piston and the other part is yielded through the ring, ring-land area, skirt and underside of the dome and the pin boss to the surroundings, i. e. lubrication oil and inner cylinder surfaces. The real process of thermal transfer is in fact more complex than indicated by this model.

The calculated temperatures are presented in Figs 2 and 3. The temperature intensity distribution

displacement, mirn

0.0500 .0750 .1000 .1250 .1500 .1750 .2000 .2250 .250

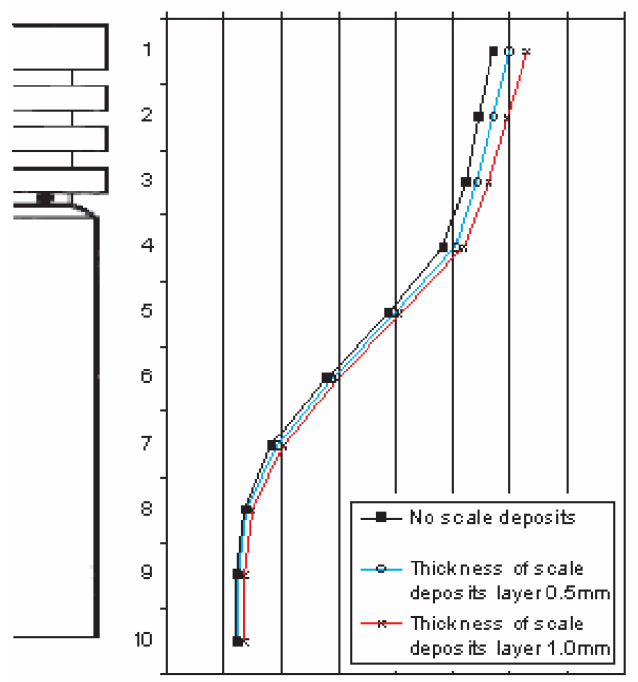

Fig 4. Temperature distribution in the piston 


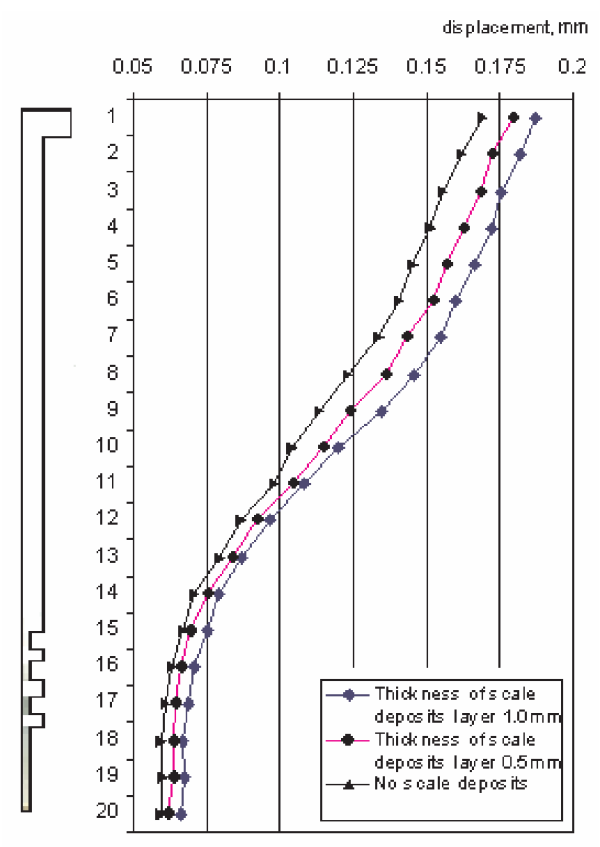

Fig 5. Temperature distribution in the piston

decreases gradually from the head of the piston to the bottom of the skirt. A maximum temperature of approximately $250{ }^{\circ} \mathrm{C}$ is obtained on the head of the piston at the point of the thrust plane. The lowest temperatures are on the skirt. A minimal temperature of about $106{ }^{\circ} \mathrm{C}$ is obtained on the tail of the skirt. A maximum temperature of approximately $165{ }^{\circ} \mathrm{C}$ is obtained on the top of the cylinder. A minimal temperature of about $101^{\circ} \mathrm{C}$ is obtained on the bottom of the cylinder.

Resolution of the reduced thermomechanical model makes it possible to obtain the thermal expansion under the highest operating temperature. For aluminum alloy a thermal expansion coefficient for $2 \times 10-5 \mathrm{~m} / \mathrm{m} \mathrm{K}$ is adopted and for gray cast iron $1,1 \times 10-5 \mathrm{~m} / \mathrm{m} \mathrm{K}$ is adopted. Fig 4 shows the thermal expansion of the piston and Fig 5 illustrates the thermal expansion of the cylinder. The expansion is very important on the crown of the piston where uniform expansion of $0,21 \mathrm{~mm}$ is obtained. The maximum expansion value of $0,188 \mathrm{~mm}$ is obtained at the top of the cylinder when the scale deposit layer thickness is $1 \mathrm{~mm}$, compared to value of $0,17 \mathrm{~mm}$ when the scale deposits are absent.

\section{Conclusion}

1.It was established that about $78 \%$ of all the examined internal combustion engines (18 engines were examined) have the scale deposit layer on the outer surface of the cylinders. The thickness of such layer on the average is approximately $1,3 \mathrm{~mm}$ and its location is at the top of the cylinder down to 3/5-ths of the cylinder height.

2. For the estimation of the influence of the scale deposit on the piston and cylinder deformations threedimensional models of the piston and cylinder were created with the help of the finite element method. Calculations showed that the scale deposit of $1 \mathrm{~mm}$ thickness provokes the increase of piston deformations up to $0,02 \mathrm{~mm}$ more and cylinder deformations up to $0,025 \mathrm{~mm}$ more as compared with the case of the scale deposit absence.

\section{References}

1. Hercamp Richard. Engine Coolants and Cooling Systems, SAE, 1999.

2. White, P. R. S.; Smith, J. and Murdoch, I. Cooling system performance evaluation, International Congress and Exposition. SAE paper 980431, Detroit, 1998.

3. Hercamp Richard D. Engine Coolant Technology, SAE, 2001.

4. Colin, R. Ferguson; Allan, T. Kirkpatrick. Internal combustion engines: Applied Thermosciences, 2nd edition, John Wiley and Sons, 2000.

5. Pikunas, A.; Garbincius, G. Influence of conditions of the main components of an internal combustion engine on fuel consumtion. Transport Engineering (Transportas), No 1 (14). Vilnius: Technika, 1999, p. 33-41 (in Lithuanian).

6. Paschkis, V. and Baker, H. D. A method for determining unsteady state heat transfer by means of an electrical analogy. Trans. ASME, Vol 64, No 2, 1942, p. 105-112.

7. Eichelberg, G. Some new investigations on old combustion engine problems. Engineering, Vol 148, 1939, p. 463466, 547-550.

8. Sanders, J. C. and Schramm, W. B. Analysis of variation of piston temperature with piston dimension and under crown cooling. Report 895, NACA, Cleveland, Ohio, 1948, p. 89-98.

9. Woschni, G. and Fieger, J. Determination of local heat transfer coefficients at the piston of a high speed diesel engine by evaluation of measured temperature distribution. SAE paper 790834, 1979.

10. Li, C. H. Thermoelastic behavior of an aluminum diesel engine piston. General Motors Research Labs, Warren, SAE paper 860163, 1986.

11. Canto, A. G.; Prata A. T. A numerical study of instantaneous heat transfer during compression and expansion in piston-cylinder geometry. Numerical Heat Transfer: Part A: Applications, Vol 38, No 3, 2000, p. 281-303.

12. Chigrinova, N. M.; Chigrinov, V. V. Analysis of Heat Stresses of the Parts of the Cylinder-Piston Group with Heat-Protective Coatings in an Internal Combustion Engine. Journal of Engineering Physics and Thermophysics, Vol 77, No 3, 2004, p. 578-589.

13. Furuhama, S. and Suzuki, H. Temperature distribution of piston rings and piston in a high speed diesel engine. 
Bull. Jap. Soc. Mech. Engrs, 1979, 22(174), p. 1788-1795.

14. Lebedevas, S.; Lebedeva, G. Mathematical model of combined parametrical analysis of indicator process and thermal loading on the diesel engine piston. Transport, Vol XIX, No 3. Vilnius: Technika, 2004, p 108-118.

15. Swallow, D.; Bruni, L.; Kinsella, F. H. and Hons, B. T. The design and development of pistons for high speed direct injection diesel engines. In the AE Technical Symposium, 1986, paper 4.

16. Reddy, J. N.; David, K. Gartling. The Finite Element Method In Heat Transfer and Fluid Dynamics, 2nd Edition, Lewis Publishers, 2000.

17. Sihling, K. and Woschni, G. Experimental investigation of the instantaneous heat transfer in the cylinder of a high speed diesel engine. SAE paper 790833, 1979.

18. Hohenberg, G. F. Advanced approaches for the heat transfer calculations. SAE paper 790825, 1979.

19. Woschni, G. A universally applicable equation for the instantaneous heat transfer coefficient in the internal com bustion engine. SAE paper 670931, 1967. 